\title{
A study abroad program for Korean nursing students in the San Francisco Bay Area: A SWOT analysis
}

\author{
Youngmee Ahn ${ }^{1}$, Kimberly Kim², Maria $\mathrm{Cho}^{2}$, Jung Eun $\mathrm{Kim}^{3}$, Narae Kang ${ }^{1}$, Bora Nam${ }^{4}$, Min Sohn ${ }^{* 1}$ \\ ${ }^{1}$ Department of Nursing, Inha University, Incheon, Republic of Korea \\ ${ }^{2}$ Department of Nursing and Health Sciences, California State University East Bay, CA, United States \\ ${ }^{3}$ Department of Nursing, San Francisco City College, CA, United States \\ ${ }^{4}$ School of Nursing, University of California San Francisco, CA, United States
}

Received: April 26, 2015

DOI: $10.5430 /$ jnep.v5n10p36
Accepted: June 23, $2015 \quad$ Online Published: July 26, 2015

URL: http://dx.doi.org/10.5430/jnep.v5n10p36

\begin{abstract}
Education in transcultural nursing care helps undergraduate nursing students develop an awareness of global health problems and improve their competency in providing nursing care to patients from diverse cultural backgrounds. For this reason, a summer study abroad program was developed for Korean undergraduate nursing students to expand their knowledge of and competency in culturally sensitive nursing care. For three consecutive years, different groups of Korean nursing students were sent to a host university in the San Francisco Bay Area to learn about health care systems and the roles of nurses in the United States. In all, 13 students participated in the program. A SWOT analysis was employed to evaluate the effectiveness of the study abroad program. For an international nursing program to be successful, it must be well-designed. Factors that affect such programs should be thoroughly investigated and, when necessary, should be revised or expanded based on the results obtained.
\end{abstract}

Key Words: Korean, Nursing education, Nursing students, Transcultural nursing

\section{INTRODUCTION}

South Korea has been a traditionally homogeneous society, but an economic surge has fueled an influx of many international visitors. In 2014, according to the Korea Immigration Service, international visitors numbered 12.7 million and foreign residents 1.7 million, ${ }^{[1]}$ which is approximately $3 \%$ of the total Korean population. Accordingly, Korean health care professionals are seeing more foreign patients than in the past. The Korean Health Industry Development Institute reported that the number of foreign patients increased rapidly from 7,900 in 2007 to 210,000 in 2013. ${ }^{[2]}$

Despite the rapidly increasing number of foreign patients, Korean nurses have limited experience with people from varied ethnic and cultural backgrounds, whether at home, in schools, or hospitals. This limited experience may reflect a lack of competency in transcultural nursing care. Researchers who have explored the transcultural competency of Korean nursing students have found that they have low cultural awareness, attitudes, perception, and self-efficacy. ${ }^{[3,4]}$

The insufficient competency of health care providers in transcultural care is directly related to low patient satisfaction and negative health outcomes. ${ }^{[5]}$ This may stem from miscommunication with patients or misunderstanding the common health problems of culturally diverse patients. Recent research has found that the quality of communication between physicians and patients can be hindered by miscommunication that arises from differences in perspectives, values, and beliefs about health and illness. ${ }^{[6]}$ According to Campbell, ${ }^{[7]}$

*Correspondence: Min Sohn; Email: sohnmin@inha.ac.kr; Address: Department of Nursing, Inha University, 100 Inharo, Incheon, South Korea. 
Korean students in an RN to BSN (registered nurse to a bachelor of science in nursing) program in the United States had difficulty communicating with patients and were less familiar with culturally related health conditions, such as obesity and sickle cell disease, and the meaning of illnesses in patients' lives.

Recently efforts have been initiated to improve the transcultural nursing competency of Korean nursing students but most of those efforts have involved the development of courses in transcultural nursing care. ${ }^{[3,8]}$ However, real experience with culturally different patients provides students with valuable opportunities to practice transcultural nursing care directly. Oh, Lee, and Schepp ${ }^{[4]}$ have observed that travel abroad and interaction with foreigners were associated with cultural awareness among Korean nursing students.

Previous studies of study abroad programs have involved mostly students from North American and European countries traveling to underdeveloped countries for public health nursing. ${ }^{[9,10]}$ While such international practicum may provide valuable educational opportunities, we have noticed that our Korean students have learning needs unique to developed countries. There students can be exposed to acutely ill patients from diverse backgrounds in hospital settings and work with clinicians who are familiar with transcultural medical and nursing care.

Thus, our transcultural study-abroad program was designed to take advantage of in-patient learning experience in an urban setting in the United States. The final course provided students with integrated experiences that involved lectures, skills and simulation laboratory, clinical observation, site visits, and cultural experiences. This type of enriched program may provide nursing students with the optimal and efficient opportunity to nurture transcultural competency. ${ }^{[11,12]}$ The San Francisco Bay Area was selected because it is wellknown for its cultural diversity and longstanding professional partnerships with the authors; the latter was critically important in establishing and maintaining the continuous communication required to develop and manage this program. The program was supported by an Innovative University Education Grant from the Korean Ministry of Education, Science and Technology and operated for 3 years $(2009-2011)$. The purpose of this paper was to describe and analyze the authors' experiences and program outcomes using a SWOT (strengths, weaknesses, opportunities, and threats) analysis.

\section{METHOD}

This descriptive study used SWOT analysis to evaluate a study abroad program for Korean undergraduate nursing students. Data were collected from September 2009 to Septem-

Published by Sciedu Press ber 2011.

\subsection{Measurements}

Students and faculty were asked to answer open-ended questions on the strengths and weaknesses of the program. They were also invited to identify components outside of the program that might be helpful (opportunities) or hindering (threats) to a successful program.

\subsection{Data collection}

SWOT analysis was based on qualitative data that were derived from meetings, interviews, essays, and email communications with the program's 13 nursing students and four faculty members.

\subsection{Program development and contents}

A general description of the program and its components is presented in Tables 1 and 2. Four faculty and two coordinators from one Korean university and two host universities in the U.S. were primarily responsible for developing and operating the program. Initially, faculty at the visiting university submitted a program proposal to the hosting universities that included the program's purpose, contents, and resources. Faculty of hosting schools reviewed the program and agreed to arrange visits to their schools and classes and clinical observation. The Korean faculty also used their personal and professional networks when contacting the institutions and hospitals that students would visit. Detailed plans were discussed by email and telephone between Incheon and San Francisco.

After program planning had been completed, third year nursing students who had completed one clinical semester in the 4-year nursing program were recruited to participate in the study abroad program. Students were knowledgeable about nursing topics and familiar with clinical environments. In additional to having successfully complete one clinical semester, selected candidates had a grade point average of 3.5 or higher on a 4.5 scale, were fluent in English and successfully completed an interview conducted in English. Students also completed a criminal background check, health examination and selected vaccinations as specified by the host university.

The course objectives were to achieve an understanding of the U.S. health care system and the roles of nurses, to compare this knowledge with the Korean experience, and to increase competency in culturally sensitive nursing care. The program consisted of five components: a preparatory session, lectures, a practicum, institutional visits, and cultural experiences. The preparatory session, which consisted of seminars and skills and physical examination laboratories, 
was held in Korea before students left for San Francisco. The program was conducted as a two-unit summer program and required 96 hours in total. Students were graded as "pass" or "fail" based on successfully passing an examination over the content included in the preparatory session, active participation during the program, and a final paper about their experiences.

During the preparatory session, students were informed, in English, about the course, the U.S. health care system, nurs- ing roles, communication skills, and documentation of the U.S. nursing care plan. The orientation occurred in the hosting university. Specific content included regulations of the U.S. Health Insurance Portability and Accountability Act (HIPPA), blood borne pathogens, and abuse of older adults, which were requirements for the host university nursing program. Faculty reviewed with students how to perform a head-to-toe health assessment and how to communicate with staff and patients in English.

Table 1. Description of the Korean study abroad program

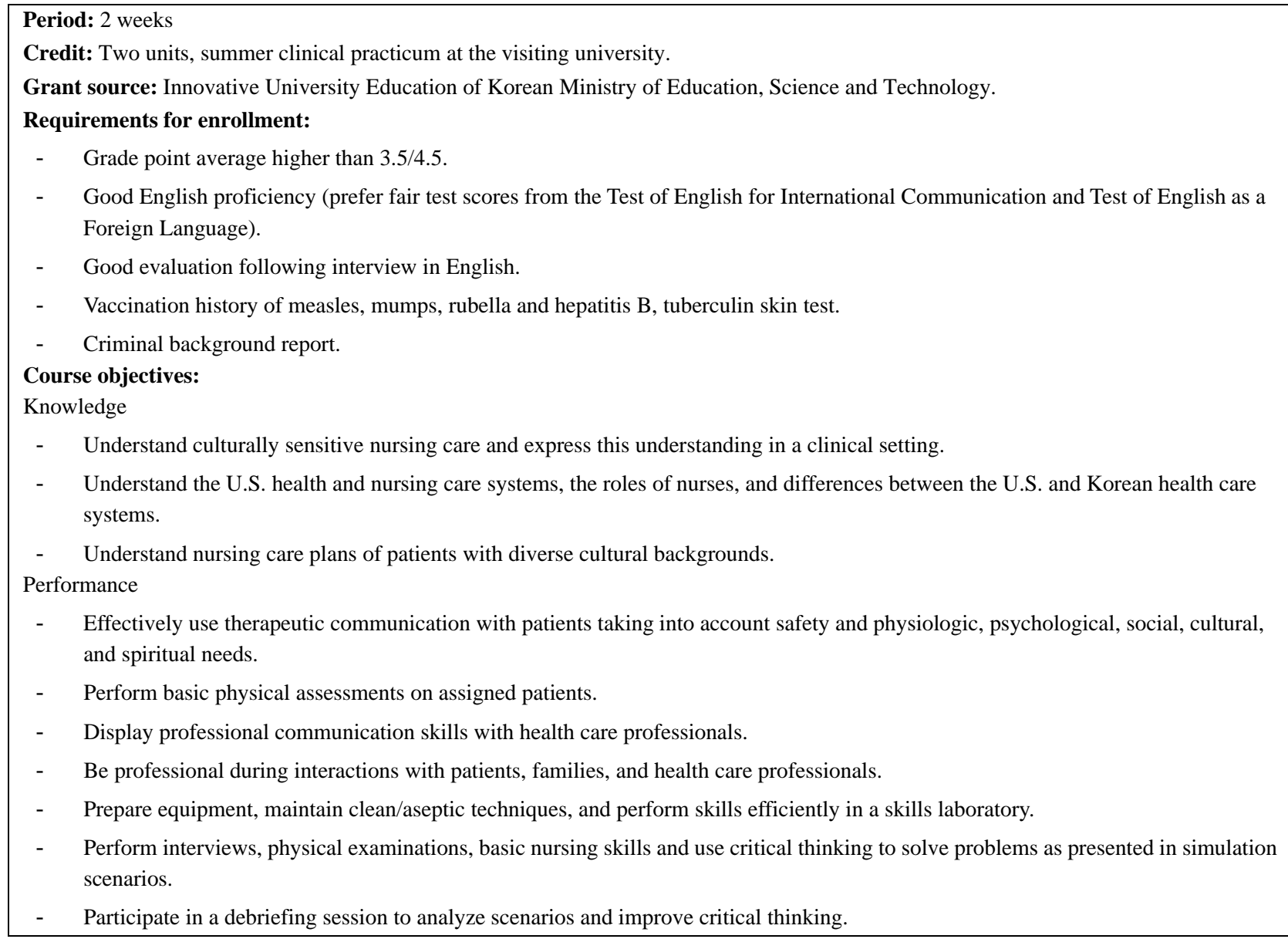

The practicum included basic life support (BLS) training, a basic nursing skills laboratory and simulation laboratory, and clinical observation in hospital outpatient and inpatient units. After students obtained BLS certification, they could participate in clinical observation. In the nursing skills laboratory, students were introduced to beginning nursing skills (e.g., head-to-toe assessment, medication administration). Students also participated in simulation sessions with a sepsis case. For clinical observation, students visited an oncology infusion center, emergency department, intensive care, maternity, neonatal care, transitional care and medical surgical units as well as a care home for older adults. Their main assignments were taking patient histories, performing physical examinations, taking vital signs, health education, and observing nursing practices. All activities were conducted under the direct supervision of staff nurses faculty members of the hosting university. For safety reasons, no visit involved invasive nursing care or medication administration. On completion of the clinical observation, students attended seminars with the faculty members of the hosting university to discuss health care and the differences and similarities between Korean and American nursing environments. 
Table 2. Components of the Korean study abroad program

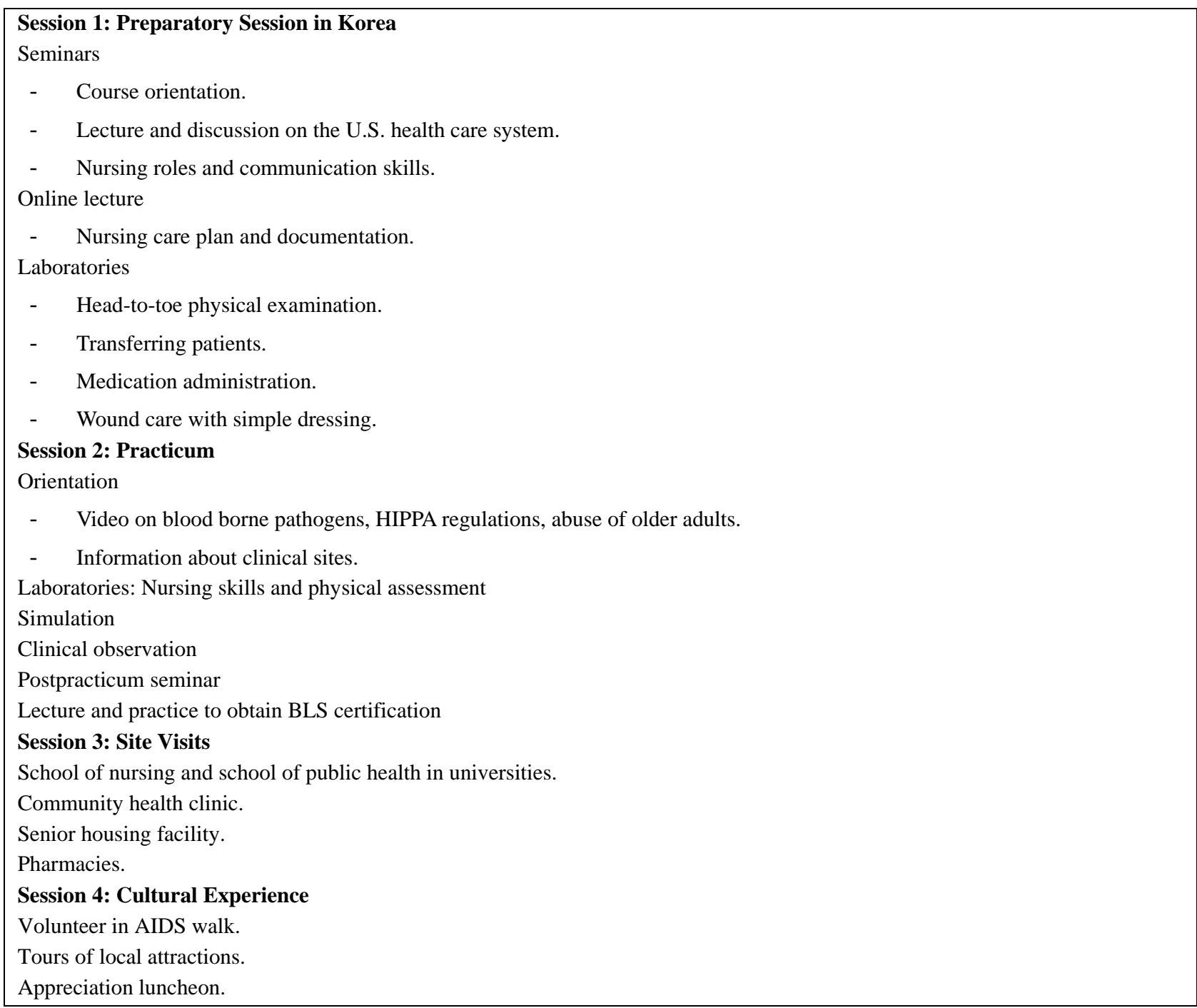

Note. HIPPA = Health Insurance Portability and Accountability Act; AIDS = acquired immune deficiency syndrome.

Visits to various institutions and cultural exposure provided students with diverse experiences. They visited two nursing schools, one school of public health, two university hospitals, a senior housing facility, and local pharmacies. For the cultural experience, students participated as volunteers in the AIDS Walk in San Francisco and had the opportunity to tour local attractions. On the final day, the Korean students hosted a lunch for the staff of host facilities to express their appreciation to those who helped them during the summer program.

\subsection{Analysis}

SWOT analysis was created in the 1950s at the Harvard Business School to provide a process to analyze case studies. It was subsequently adopted widely as a business tool ${ }^{[13]}$ and allowed institutions to better position and improve pro- grams. Strengths and weaknesses reflect internal competencies and resources that institutions or individuals possess. Opportunities and threats are external factors that might affect programs; they could be individuals, resources, circumstances, trends, or events with positive or negative consequences. SWOT analysis can also help nursing educators bolster strengths, take advantage of opportunities, overcome threats, and minimize the weaknesses of educational programs. ${ }^{[14]}$

\section{RESULTS}

\subsection{Strengths}

The most frequently reported strength of our study abroad program was the integrated educational experiences that included language learning, transcultural experiences, and evidence-based nursing care. Students were able to interact 
with local faculty, students, nurses, physicians, and patients in various environments such as lectures, nursing skills laboratories, and clinical observations. Students and faculty commented that this integrated learning opportunity provided lived experiences of nursing education environments and clinical settings in the United States. The most frequently reported experiences involved communication style, classroom atmosphere, and equipment and health care services performed by multidisciplinary team in hospitals.

Other notable strengths of the program were the bilingual and bicultural capabilities of local faculty. Because local faculty were familiar with both the Korean and American health care systems, they could articulate how health care providers worked differently or similarly in both countries. They also facilitated student interaction with other local nursing faculty, nurses, other health care providers, local students, and patients. In this environment, the Korean students felt less stress and concern about misunderstandings caused by language or cultural differences.

Other strengths included the informative preparatory session and obtaining BLS certification, which were helpful from individual and program perspectives. In addition, the Korean students reported that receiving two units of credit from their university and a fee waiver were definite program strengths.

\subsection{Weaknesses}

According to students and faculty, the most glaring program weaknesses were its short length and high cost. Students felt that 2 weeks was not enough time to meet some of the course objectives. Although the Korean government provided $\$ 2,000$ per student, those funds were dedicated to program expenses. Students had to finance their flights, lodging outside of the host nursing school, and food. Students were satisfied with their accommodations but wanted to use the school library to prepare for the practicum and seminars while they were staying inside of the school.

Lack of direct patient care was cited as another significant weakness. Because the program was short and students were not registered as full-time students of the local nursing school, they were unable to obtain official credits or benefits from the host school, which included malpractice insurance. As a result, students had limited access to patient information and nursing care, which was understandable for patient safety and confidentiality.

\subsection{Opportunities}

Students and faculty reported that the program's most significant opportunities were the grant from the Korean government and the commitment of the visiting school. The government grant was mainly used to cover the direct costs of program development and operation. The visiting school also supported the program indirectly by giving course credits, a tuition waiver, and health insurance to students. Another opportunity was the well-established understanding of the importance of culturally competent nursing care within universities, hospitals, and community in both regions. Faculty and staff in the San Francisco Bay Area truly welcomed students and provided a variety of learning opportunities despite a lack of time, personnel, and resources. The summer break, the time period allocated for the program, allowed students, faculty, and staff to concentrate on the program without the burden of duties associated with regular semesters.

\subsection{Threats}

Students and faculty reported the major threats to this program were insufficient language skills and cultural differences between local faculty and students. Even though students had passed a written examination and were interviewed before enrollment in the program, their language skills were too rudimentary for them to express their thoughts during program activities. Students reported that they could understand reading material, quizzes, and lectures, but they were unable to fully articulate their thoughts during classroom discussions.

Students and faculty often encountered awkward situations in the classroom and clinical settings. For example, the Korean students tried to show their respect for faculty and staff by not asking too many questions or by avoiding eye contact. In the West, however, these behaviors can be considered lack of interest or disrespect.

\section{Discussion}

The authors conducted SWOT analysis to describe the strengths, weaknesses, opportunities, and threats to a shortterm study abroad program for Korean nursing students. The students and faculty who participated in this program reported that it provided excellent opportunities to learn culturally sensitive health issues and transcultural nursing care using safe, practical, and integrated methods. All of the students met the course objectives, passed course requirements (e.g., BLS certification, quizzes), and participated in all classes, laboratories, and clinical observations. In seminars, the students expressed a sound understanding of the health care system and nursing roles in the United States, as compared with the Korean system. They also stated that they had become more competent in providing culturally sensitive nursing care to patients. These perceived benefits are consistent with the literature. Previous studies have indicated that study abroad programs for undergraduate nursing students provide obvious benefits to students, schools, and commu- 
nities. ${ }^{[15]}$ In addition, the intercultural experience provides students with broader educational benefits: cognitive development, professional development, personal maturation, and increased cultural understanding. ${ }^{[16]}$

However, the program's short length and high cost should be overcome to continue this type of program. Afriyie Asenso and their colleagues ${ }^{[17]}$ found that Canadian nursing students experienced three stages of learning during their 3-week study abroad in Zambia. At the outset, students needed time to adjust to the local environment; next they started to engage in learning activities; finally they started critical thinking, which led to more significant learning experiences. Our 2-week model might not have afforded enough time for the development of these valuable stages. In addition, our program's high cost was a significant weakness. The literature has described most study abroad programs as moving students from developed to developing countries. In such cases, cost might be a less important issue because living costs in developing countries are usually low. However, sending students from developing countries to developed countries poses obvious financial concern. Kent-Wilkinson and colleagues ${ }^{[15]}$ found that financial burden was one of the most significant barriers for their study abroad program. In developing and operating our program, we found that potential funding for educators is currently available from the Ministry of Education, the Korean International Cooperation Agency, the Overseas Korean Nurses Association, the Ko- rean University Council for Social Services, and others. In addition, educators should not overlook the availability of support from their own universities. For example, most universities have international offices dedicated to establishing international partnerships and have staff, space, and experience with international institutions. They often encourage the overseas involvement of their students and faculty.

\section{CONCLUSION AND IMPLICATIONS}

The study abroad program provided an opportunity for Korean undergraduate nursing students to learn about transcultural nursing care for patients from diverse cultural backgrounds, within different health care systems, and the roles of health care providers in the United States in a relatively short time. Although the program's benefits were many, the language barrier, high cost, and cultural barriers in the learning environment were weaknesses to be overcome if future program are to be successful. Nursing educators worldwide may need to establish a consortium for study abroad programs to share placements, strategies, and funding resources.

\section{ACKNOWLEDGeMENTS}

This paper was supported by Inha University Research Grant and an Innovative University Education Grant from the Korean Ministry of Education, Science and Technology.

\section{Conflicts of InTEREST Disclosure}

The authors declare that there is no conflict of interest.

\section{REFERENCES}

[1] Korea Immigration Service. Immigration Statistics. 2015. Available from: http://www.immigration.go.kr/HP/COM/bbs_003/L istShowData. do?strNbodCd=noti0097\&strWrtNo=163\&str AnsNo=A\&strOrgGbnCd=104000\&strRtnURL=IMM_6070\&strAl 10rgYn=N\&strThisPage=1\&strFilePath=imm/

[2] Korea Health Industry Development Institute. Health Service Statistics. 2014. Available from: http://www.khiss.go.kr/tr eeManager.do?task=treeFrm\&vw_cd=MT_ITITLE\&list_id =358_E\&htxt_code=125369725751510746110771881221239

[3] Kim NH, Lim SY. Relationships between multicultural awareness, multicultural attitude and multicultural efficacy among nursing students. Multicultural Education Studies. 2014; 7: 169-184. http: //dx.doi.org/10.14328/MES. 2014.12.31.169

[4] Oh H, Lee JA, Schepp KG. Translation and evaluation of the Cultural Awareness Scale for Korean nursing students. International Journal of Nursing Education Scholarship. 2015; 12(1): 1-8. PMid:25719340 http://dx.doi.org/10.1515/ijnes-2014-0067

[5] Kim KS, Ahn JW, Kim JA, et al. A comparison study using mixed methods on foreign residents' satisfaction with Korean health care services. Journal Korean Academy of Nursing. 2014; 44(1): 86-96. PMid:24637289 http://dx.doi.org/10.4040/jkan.2014.44. 1.86

Published by Sciedu Press
[6] Paternotte E, van Dulmen S, van der Lee N, et al. Factors influencing intercultural doctor-patient communication: a realist review. Patientient Education Counseling. 2015; 98(4):420-45. PMid:25535014 http://dx.doi.org/10.1016/j.pec.2014.11.018

[7] Campbell ET. Teaching Korean RN-BSN students. Nurse Educator 2009; 34(3): 122-125. PMid:19412054 http://dx.doi.org/10. $1097 /$ NNE . 0b013e31819fb468

[8] Peek EH, Park CS. Effects of a multicultural education program on the cultural competence, empathy and self-efficacy of nursing students. Journal of Korean Academy of Nurses. 2013; 43(5): 690-696. PMid:24352000 http://dx.doi.org/10.4040/jkan.2013.43. 5.690

[9] Burgess CA, Reimer-Kirkham S, Astle B. Motivation and international clinical placements: shifting nursing students to a global citizenship perspective. International Journal of Nursing Education Scholarship. 2014; 11(1): 1-8. PMid:24739330 http://dx.doi.o $\mathrm{rg} / 10.1515 /$ ijnes-2013-0056

[10] Long T. Influence of international service-learning on nursing student self-efficacy toward cultural competence. Journal of Nursing Education. 2014; 53(8): 474-478. PMid:25054475 http://dx.doi . org/10.3928/01484834-20140725-02

[11] Charles L, Maltby H, Abrams S, et al. Expanding worldview: Australian nursing students' experience of cultural immersion in India 
Contemporary Nurse. 2014; 48(1): 67-75. http://dx.doi.org/1 $0.1080 / 10376178.2014 .11081928$

[12] Sloand E, Bower K, Groves S. Challenges and benefits of international clinical placements in public health nursing. Nurse Education. 2008; 33(1): 35-38. PMid:18091470 http://dx.doi.org/10.10 97/01.NNE. 0000299493.00249.2d

[13] Panagiotou G. Bringing SWOT into focus. Business Strategy Review. 2003; 14(1): 8-10. http://dx.doi.org/10.1111/1467-8616. 00253

[14] DeSilets L, Dickerson P. SWOT is useful in your tool kit. Journal of Continuing Education in Nursing. 2008; 39(5): 196-197. PMid:18512578 http://dx.doi.org/10.3928/00220124-200 80501-01
[15] Kent-Wilkinson A, Leurer MD, Luimes J, et al. Studying abroad: Exploring factors influencing nursing students' decisions to apply for clinical placements in international settings. Nurse Education Today. 2015; 35(8): 941-947. PMid:25846198 http://dx.doi.org/10. $1016 / j$.nedt . 2015.03.012

[16] Koskinen L, Tossavainen K. Study abroad as a process of learning intercultural competence in nursing. International Journal of Nursing Practice. 2004; 10(3): 111-120. PMid:15149458 http: //dx.doi.org/10.1111/j.1440-172X.2004.00470.x

[17] Afriyie AB, Reimer-Kirkham S, Astle B. In real time: exploring nursing students' learning during an international experience. International Journal of Nursing Education Scholarship. 2013; 10(1): 227-236. http://dx.doi.org/10.1515/ijnes-2012-0045 